\title{
Involving people with dementia and their carers in dementia education for undergraduate healthcare professionals: a qualitative study of motivation to participate and experience
}

\author{
Zoe Cashin, ${ }^{1}$ Stephanie Daley, ${ }^{2}$ Molly Hebditch, ${ }^{3}$ Leila Hughes, ${ }^{2}$ and Sube Banerjee ${ }^{2}$ \\ ${ }^{1}$ St Richards Hospital, Chichester, UK \\ ${ }^{2}$ Centre for Dementia Studies, Brighton and Sussex Medical School, Brighton, UK \\ ${ }^{3}$ School of Health Sciences, University of Surrey, Guildford, UK
}

ABSTRACT

Background: There is a need to improve dementia education to prepare future generations of healthcare professionals to deal with the increasing challenges they will face. Time for Dementia is an innovative undergraduate education program for medical, nursing, and paramedic students in the south of England. Success of the program is dependent upon the participation of families (people with dementia and their carers). This qualitative study seeks to explore the motivation and experiences of the families taking part in the program.

Methods: A topic guide was developed to understand factors influencing motivation and retention. A purposeful sample of participant families, who had at least 12 months of involvement in the program, were selected from a cohort of 282 families and were invited to take part in an in-depth qualitative interview. Interviews were audio recorded, transcribed verbatim, and analyzed using thematic analysis. This was subsequently refined in an on-going process of analysis aided by the use of Nvivo 11. Interviewing stopped when thematic saturation was reached.

Results: Eighteen families took part in an in-depth qualitative interviews. Four themes were identified from the analysis. These themes were motivators, value to family, value to the person with dementia, and student factors.

Conclusions: This study identifies underpinning factors that motivate families to join dementia education programs and the impact of such programs upon them. We found that engagement in such programs can have therapeutic benefits to participants, and do not cause harm. These findings can be used to strengthen recruitment and enhance family involvement in similar programs.

Key words: dementia, carers, nursing

\section{Introduction}

The growth in the numbers of people with dementia, and with it their need for healthcare, demands that the future workforce needs to be sufficiently skilled to work with people affected by the condition (Banerjee et al., 2016). Delivering good quality healthcare to people with dementia in non-dementia-specialist settings such as acute hospitals and primary care can be complex. As patients in general hospitals, people with dementia have particularly poor outcomes, including extended hospital stays,

Correspondence should be addressed to: Stephanie Daley, Clinical Research Fellow, Centre for Dementia Studies, Brighton and Sussex Medical School, Brighton, UK. Phone: 00447717 571679; Fax: 00441273 872941. Email: s.daley@bsms .ac.uk. Received 12 Jan 2018; revision requested 15 May 2018; revised version received 07 Jul 2018; accepted 09 Jul 2018. First published online 6 December 2018. increased mortality rates, falls, functional deterioration, disorientation, malnutrition, dehydration, increased dependency, depression, and superimposed delirium (Dewing and Dijk, 2016). Barriers to effective healthcare delivery to patients with dementia include poor communication, lack of co-ordination between professionals, and insufficient dementia awareness (Bunn et al., 2014), as well as dehumanizing and unsatisfactory care (Morhardt, 2014). Family carers of in-patients with dementia have reported inadequate support, that their contributions are not recognized, and the overall hospital care of the people for whom they care for to be unsatisfactory (Bunn and Sworn, 2012; Dewing and Dijk, 2016). There are equivalent issues and needs in primary and community care settings, and the need for all primary and 
community care professionals to have the skills and knowledge to work compassionately with patients with dementia and their carers has been widely identified (Department of Health, 2013, 2016; Downs and Lord, 2017).

A healthcare system and workforce must be patient centered and equipped for people with dementia and their carers (Banerjee, 2015; Department of Health, 2009, 2015). One approach to improve dementia education at an undergraduate level is based on the longitudinal clerkship model of healthcare education, whereby students have contact over time with a patient with a long-term condition, such as dementia (Alushi et al., 2015; Banerjee et al., 2016). The majority of such programs are found in the United States, last no more than 12 months, and are non-compulsory in nature. There are encouraging positive impacts on learning about dementia and attitudes toward it (Alushi et al., 2015).

In view of this, in 2014, the Time for Dementia (TFD) program was established as a component of the curricula for medical, nursing, and paramedic students at the Brighton and Sussex Medical School (BSMS) and the University of Surrey (Banerjee et al., 2016). All students visit a person with dementia and their family in pairs every three months for a period of two years, as well as receiving supporting lectures and reflective practice sessions. The program is unique in four ways: first the inclusion of multi-professional groups, second the compulsory nature of the program, third the active involvement of over 350 people with dementia with varying levels of disease severity along with their carers, and finally the collaboration between universities, the voluntary sector (Alzheimer's Society), and local NHS trusts.

While people with dementia and their carers have been involved in different models of dementia education, there is a gap in the literature as to their subjective experience, and factors influencing their engagement. The TFD program is reliant upon the on-going recruitment and retention of large numbers of participant families, but increasingly education programs will need to include people with dementia and their families as mentors to build accurate knowledge, positive attitudes, empathy, and compassion. We need to know how best to recruit and retain families affected by dementia in educational programs of all sorts. There are equivalent concerns about recruitment and retention in research studies in dementia and the frail elderly, in general. Data from such educational programs may also be of value in understanding this (Mody et al., 2008; Watson et al., 2014). Therefore, we completed a qualitative study to enable us to understand factors influencing family engagement by addressing two specific research questions:
1. What are the factors that motivate families to join the TFD program?

2. What factors contribute to the retention of families in the TFD program?

\section{Methods}

Sample and Setting: The study took place in the south of England in 2016. Participants came from the 282 families, who had been part of the TFD program for 12 months, and had received three visits from medical, nursing, or paramedic students. Family participants were dyads of a person with a diagnosis of dementia and their identified carer (which included spouses, adult children, and other family members, as well as friends). Families were recruited to TFD by the Alzheimer's Society, and consent to take part in the educational program was sought for both the person with dementia and their carer. Family participants who had withdrawn from the wider TFD program were excluded from this research study. NHS Research Ethics approval was obtained.

Procedure: After enrollment into the TFD program, all family participants were invited to join the related research study. Study information was provided, and families consented to being part of the study. Capacity was assessed at all research visits, and consultee opinion was sought if capacity was assessed as lacking. Purposeful sampling was used to approach an equal number of family dyads from each of the four student cohorts at both universities (two medical and two nursing/paramedic cohorts) undertaking the program. Families were approached for a joint (person with dementia and carer) interview, although an opportunity for an individual interview was also offered. During the final round of interviews, further purposeful sampling was used to approach participants with dementia who had a lower level of cognitive impairment, as measured by the Mini-Mental State Examination (Folstein et al., 1975). We used a qualitative design and thematic analysis that underpinned the analysis.

The interviews were conducted by $\mathrm{ZC}, \mathrm{MH}$, and $\mathrm{LH}$. The interviews, lasting between 30 to 60 minutes, were conducted with the person with dementia and their carer together in their own homes. A topic guide was developed from a review of the literature and was subsequently amended during the analysis phase. The topic guide explored motivation to join the program, the experience of the visits and of being involved in the program, perceived student learning, and relationship with students and program management. Interviews were tape recorded, transcribed verbatim, and checked for accuracy. 
Table 1. Characteristics of the person with dementia participants $(n=18)$

\begin{tabular}{|c|c|c|}
\hline CHARACTERISTIC & TYPE & NUMBER (\%) \\
\hline Gender & Female & $11(61)$ \\
\hline \multirow{3}{*}{ Age } & $65-75$ years & $4(22)$ \\
\hline & $76-85$ years & $11(61)$ \\
\hline & $86+$ years & $3(17)$ \\
\hline \multirow[t]{4}{*}{ Diagnosis } & Alzheimer's Disease & $12(66)$ \\
\hline & Frontotemporal & $1(6)$ \\
\hline & Mixed Diagnosis & $4(22)$ \\
\hline & Dementia Unspecified & $1(6)$ \\
\hline \multirow[t]{3}{*}{ MMSE score } & $21-30$ (mild) & $9(50)$ \\
\hline & $11-20$ (moderate) & $8(44)$ \\
\hline & $0-10$ (severe) & $1(6)$ \\
\hline \multirow[t]{2}{*}{ Ethnicity } & White/British/European & $17(92)$ \\
\hline & Black/African/Caribbean/ & $1(6)$ \\
\hline \multirow[t]{6}{*}{ Main/previous occupational group } & Administrative/secretarial & $4(22)$ \\
\hline & Skilled trades & $2(11)$ \\
\hline & Sales/customer services & $2(11)$ \\
\hline & Associate professional/technical & $1(6)$ \\
\hline & Manager/director/senior official & $5(28)$ \\
\hline & Professional & $4(22)$ \\
\hline
\end{tabular}

Analysis: The analysis took part in four phases. First, after the first nine interviews, ZC and SD manually coded four transcripts each by categorizing meaningful segments of texts into descriptive codes. They met together to review their respective preliminary codes to identify areas of differences and agree upon an initial coding framework and subsequent amendment to the topic guide.

Second, the next five transcripts were analyzed using the initial coding framework, and a more focused framework of nine themes was developed. A decision was made at this stage to carry out interviews with participants with dementia with lower levels of cognitive impairment to facilitate the recall of student visit details.

Third, nine further interviews were undertaken and were analyzed with the support of the software program, Nvivo version 11 (QSR International, 2015), which allowed for the sytematic collation and review of the data grouped within each code. This was reviewed on an on-going basis using constant comparison techniques (Glaser and Strauss, 1967), which involved the researchers comparing coding and data between earlier and new transcripts in order to check on the use of codes for consistency and to begin to identify the relationships that might exist between different codes. No further interviews were undertaken at this stage, as thematic saturation was reached, where no new themes were identified from the data. A final coding framework was agreed from this final round of analysis and four themes were agreed.

The fourth stage included the two researchers discussing and developing an understanding of the relationships between the themes in order to understand initial engagement and continued participation in the TFD program. During this time, ZC and SD met on a weekly basis to discuss and agree on emerging themes.

The researchers maintained reflexivity in two ways (Allsop, 2013). First, the analysis was undertaken jointly by ZC and SD. SD provided regular academic supervision to ensure that there were ongoing opportunities for reflexivity and for dialogue and thorough discussion of emerging ideas, perspectives, and assumptions, thus enhancing the rigour of the research. Second, ZC maintained a fieldwork diary in order to enable reflection of the potential impact of her role as a medical student on the research process.

\section{Results}

Participants: In total, 18 interviews were completed, involving 36 participants. The characteristics of the person with dementia participants are shown in Table 1, and carer participants are shown in Table 2.

Overall findings: Four core themes, each with subthemes, were identified from the data analysis: motivators, value to family, value to person with dementia, and student factors.

\section{Theme one: Motivators}

There were four sub-themes that acted as motivators to join the program. These were altruism, dementia knowledge, understanding and recommendation. 
Table 2. Characteristics of the carer participants $(n=18)$

\begin{tabular}{|c|c|c|}
\hline CHARACTERISTIC & TYPE & NUMBER (\%) \\
\hline Gender & Female & $10(56)$ \\
\hline \multirow{2}{*}{ Relationship with person with Dementia } & Spouse/Partner & $14(78)$ \\
\hline & Son/Daughter & $4(22)$ \\
\hline Ethnicity & White/British & $18(100)$ \\
\hline \multirow[t]{6}{*}{ Main/previous occupational group } & Administrative/secretarial & $4(22)$ \\
\hline & Skilled trades & $1(6)$ \\
\hline & Caring/leisure/other & $1(6)$ \\
\hline & Associate professional/technical & $4(22)$ \\
\hline & Manager/director/senior official & $4(22)$ \\
\hline & Professional & $4(22)$ \\
\hline
\end{tabular}

Altruism was identified as many of those interviewed reported that they had joined the program because they felt they were helping others and joining the cause of improving the treatment and care of people with dementia in the future. Improved dementia knowledge and awareness was an important motivating factor. Many of the participants reported that they wanted to join the program in order to educate students now, so that as future health care professionals they will be more informed and dementia aware.

"My aim is to make the world more aware of what dementia is" (p.18, Person with Dementia).

Recommendation was also identified as almost half of the participants were signposted to the TFD program from a community professional such as Alzheimer's Society worker. Additionally, many of the families joined on carer initiation, who would sign up both the person with dementia and their self to the program often with the belief that it would be of value to the person with dementia.

"..if he (carer, husband) thinks of something and then thinks it will be good for in the long run.. I might forget it the next minute, but I know he's talked to me about it, so then that's the way" (p.16, Person with Dementia).

Several participants described seeing no harm in taking part in the program as being a motivating factor for them. This included both the program being unlikely to be distressing to the person with dementia, as well as some ambivalence about taking part with an almost "why not" approach.

"There was nothing to be gained by not joining in" (p.21, Carer).

\section{Theme two: Value to family}

There were five sub-themes that contributed to the perceived value to families: making a difference, enjoyment, continuity, student learning, and carer voice.

For many of the participants, the feeling of contributing and making $\boldsymbol{a}$ difference was a significant feature of the perceived value of participating in the program.

"I think what you gain is the feeling that in the future people may be treated differently... if by talking to one person (with dementia) then one other person gets treated differently, maybe better, or understood better... then it's worth all the effort" (p.35, Carer).

Participant enjoyment of the visits with the students was identified as a perceived value to families promoting retention on the program.

"We enjoy a cup of tea... together, we have a little break and a chat, chitchat away with them" (p.22, Person with Dementia).

The continuity of the visits with the same students and building a relationship was perceived as a positive outcome of the program. Additionally, the building of a rapport and trust in the relationship as part of this continuity was also valued.

The majority of participants expressed the importance of having feedback about student learning, either from the students and/or program organizers. In some situations, a positive impact was implicitly obtained or hoped for, but for others, there was some uncertainty about the impact of student learning.

"I feel that whatever we do, whatever we say, they will learn something from it, about me" (p.18, Person with Dementia).

Carer participants described how being given a carer voice and being able to talk about the challenges of caring was a perceived value of the program 
to them. In particular, being able to share what life as a carer is really like and having the time and opportunity to talk. Being able to open up and express feelings in front of the students was also valued.

"You find friends disappear, and don't understand and don't want to know. So it's nice to, sort of, actually to be able to talk about things that are happening, and how you feel" (p.23, Carer).

\section{Theme three: Value to person with dementia}

There were two sub-themes that contributed to the perceived value to person with dementia. These were social interaction and own environment.

Both the person with dementia and carer participants talked about the significant value of the social interaction aspect of the value for the person with dementia. The value of the visits taking place at home in their own environment emerged as of value for the person with dementia. In some instances, the carer was the one who described the benefit of the person with dementia being at home for the visits.

"I think overall the atmosphere is good, relaxing because we're in our own environment" (p.7, Carer).

\section{Theme four: Student factors}

There were three sub-themes identified as student factors: interpersonal attributes, approach to learning, and fit between family and student.

A significant number of participants described the interpersonal attributes and behavior of the students, in terms of how they were experienced by the families, and this seemed an important aspect of the visits and overall experience. In particular, how warm and friendly the students were, how empathetic and understanding they were, and how they actively listened to the families.

Several participants described the students' practical and active approach to learning in a positive context, whereas others felt that they wished for more formality in the student's learning objectives. Additionally, some described a reticence in students to take a lead during the visits.

"They seem interested in how I feel, and how we get on... they do seem interested in me as a person you know" (p.22, Person with Dementia).

An important factor influencing family experience of the program was the fit between family and student pair. For many, the relationship was considered positive in nature.

"I think it's reached a very good stage and atmosphere that we look forward in a way to when they say they're coming again" (p.7, Carer).

\section{Discussion}

This study is the first to have identified what motivates people with dementia and their carers to take part in educational initiatives for healthcare professionals in training such as TFD. It also explores their experiences of the TFD program. It identified four themes that help us understand the factors influencing people with dementia and their carers to be both motivated to participate and remain engaged in the TFD program. It is evident that families hold specific expectations about participating in the TFD, both in terms of desired outcomes (e.g., for there to be improved knowledge about dementia), as well as expectations about student behavior (e.g., students should be keen and eager and to learn). These expectations influence motivating factors and also impact upon the experience of the visits. If a positive experience takes place and expectations are met, it is likely that families will continue to take part in the program. These underpinning factors may well be applicable to other similar educational and research programs where contact over time is required (Watson et al., 2014).

\section{Motivating factors}

Families in this study were driven to join the program by the desire to improve the current and future healthcare workforce, in regard to their knowledge, attitudes, and awareness of dementia. Carers specifically felt that their role in the care of the person with dementia was undervalued by current healthcare professionals and this was of concern to them. Evidence supports the fact that people with dementia and their carers are a functional unit, and family carers need to be acknowledged, engaged, and reassured by the healthcare professionals they come into contact with (Douglas-Dunbar and Gardiner, 2007; Jurgens et al., 2012).

The study identified that carers primarily initiated joining the program. This is consistent with the wider literature that carers are key influencers in decision making processes for the person with dementia, especially as cognitive impairment becomes more severe (Black et al., 2013; Sugarman et al., 2001). This is an important finding in considering future recruitment and on-going engagement in the program. Carers need to feel the program is a worthwhile activity because they are making a time commitment on top of caring responsibilities, and they need to consider the time of the person with dementia (Sugarman et al., 2001). This study demonstrates the key role carers play in the decisionmaking process of joining the program. Carers were often responsible for communicating the requirements of the program to the person with dementia, gatekeeping its suitability for the person, and, at 
times, making the decision in the best interests for the person with dementia to participate.

\section{Retaining factors}

Value to the family and to the person with dementia as well as student factors were key factors influencing on-going participation in the program. Family enjoyment of the student visits was an important factor underpinning retention. This data fills a gap in the literature about the experiences of families in dementia education programs. Feedback from other programs has tended to be focused predominantly on student experience, rather than family accounts (Jefferson et al., 2012; Morhardt, 2006; Morhardt, 2014).

The TFD program is the first of its kind to have a two-year duration with consistent visits with the same paired groups of students and families at scale. The findings show that this continuity of the visits fosters positive relationships, reciprocal sharing, and familiarity for the person with dementia. These were important factors for family members. This also appears to enhance the benefit of the program over time. The long-term commitment, therefore, seems to be a positive factor in recruitment and engagement rather than a complication.

Families reported benefit from their belief that they were making a difference to students learning about dementia. The perception that they were changing attitudes about dementia was critical. This was both a motivating and retaining factor, as meeting initial expectations and on-going expectations about student learning allowed for families to feel that their time was being well spent. Many families believed strongly that experiential learning was better than anything taught in the classroom. This is consistent with the literature that suggests theoretical input alone does not give students the necessary skills to work with people with dementia, and that experiential learning through exposure early in undergraduate education is a potentially powerful strategy (Alushi et al., 2015; Banerjee et al., 2016).

The value of the program in allowing carers to talk about their experiences was identified as an important factor. Therefore, meeting the expectations and needs of carers is important, given their crucial role in both initiating and ensuring on-going engagement in the program. For the person with dementia, having the opportunity to have company and social interaction was important, as well as the feeling that someone was coming to see them specifically. This finding is consistent with the evaluation findings from the BUDDY and PAIRS programs in the United States (Jefferson et al., 2012; Morhardt, 2006). Interestingly, the findings from the BUDDY program suggested that people with dementia felt a responsibility for educating the student and creating a sensitive physician for the future, but this was not reflected in this study. This might be due to differences in disease severity as other educational programs only involved those with very mild dementia, who were living independently, and had more responsibility in the program (Morhardt, 2014).

The interpersonal behavior of the students was an important aspect in the retention of families. An eagerness to learn and preparedness of the students was an important aspect, the desire for greater formality and structure was expressed and the reticence of the students in taking control was seen as an area for improvement. In previous programs, such as BUDDY and PAIRS, the students were self-selected for their interest in dementia, and they received high levels of individual support throughout the program, which ran for a much shorter time (Jefferson et al., 2012; Morhardt, 2006). In TFD, it is a compulsory aspect of the curriculum that means all students, no matter what their prior orientation towards dementia, have the exposure and experience. This does mean that there are challenges in regard to their preparedness and approach to the visits. The fit between each student pair and their family was an important aspect, and many families expressed a desire to be actively matched with student pairs, although to date, this has not taken place due to logistical issues. However, the value of the program is very heavily waited on fit and the relationship that is fostered between the students and the families over the two-year period, so supporting this is of importance.

This study has sought to understand the factors that motivate families to join and remain involved in a dementia focused educational program. Altruism alone cannot be relied upon as a recruitment strategy. This study has shown that families want to make a difference to future healthcare provision and want students to learn, as well as develop a positive relationship with student learners. Additionally, by acknowledging the role of the carer as a central figure in the recruitment, facilitation and monitoring of on-going visits, retention of families in such programs can be maintained.

\section{Strengths and limitations}

There are four main limitations to the study. First, the sample of families interviewed had been involved with the program for 12 months. The perspectives of families who decided not to join the program, or withdrew early from the program, were therefore not captured in this study. Those families may have expressed more dissatisfaction with the program 
or anger or ambivalence about the program in their interviews. Therefore, these findings only relate to those families who were satisfied with the program; not all families. However, the refusal and drop-out rate for TFD is low, $15 \%$ per year, with the main reasons being death, family ill-health, or change of living arrangements rather than dissatisfaction with TFD. Second, the recall problems inherent in dementia as it progresses may limit the extent to which these findings can fully represent the views of people with more severe dementia. This is mitigated to an extent by the carer interviews, which will have validity across the range of dementia severity. Third, the specific nature of the tasks and supports available in TFD may limit the generalizability of the data generated to other educational and research programs. Fourth, there was limited ethnic diversity in the participants interviewed and the economic status of carer participants was not directly identified, other than through previous/main occupational group. This limits the extent to which conclusions might be drawn about how ethnicity, social, and economic characteristics of participants might influence who might engage in dementia education programs and their experiences. Further research is needed in this area.

There are three main strengths in this study. First, the relative lack of research about factors influencing engagement in families who participate in dementia education means that these data make a useful contribution towards understanding why families affected by dementia sign up to an educational program like TFD. Second, the good quality approach to data collection and analysis and incorporating reflexivity means that the findings are solidly based in the experience and testimony of the people with dementia and carer included in the research. Third, purposeful sampling and completion of 18 interviews, stopping only at the point where no new themes were emerging, enhances the validity and the generalizability of the study findings.

\section{Conclusions}

We need to be able to recruit and retain people with dementia and their family carers in novel educational initiatives, such as the Time for Dementia (TFD) program, if we are to improve the quality of the future healthcare workforce in terms of its ability to meet the challenges of long term conditions and multimorbidity as exemplified by dementia. In this study, we have identified the factors that promote engagement with such programs. There are parallels with the needs of research projects, which often need to be longitudinal in dementia and frailty given the nature of illnesses involved (Mody et al., 2008; Watson et al., 2014). Therefore, the data generated may have value in the design and conduct of both educational and research programs in dementia. Our data support the need to consider at the design and conduct stages expectations, motivators, and positive experience factors including the value to family, value to the person with dementia; and student factors (researcher factors in research studies). This provides detail on how this might be operationalized to enable educational and research participation that is successful for educators, researchers, and people with dementia and their family carers alike.

\section{Conflict of interest}

None.

\section{Funding}

This project was funded by Health Education England Kent Surrey and Sussex (HEE KSS). The views and opinions expressed here are those of the authors and do not necessarily reflect those of HEE KSS, the National Health Service, or the Department of Health. The sponsor of the study had no role in the design of the study, the data collection, data analysis, interpretation of the results, the writing of the manuscript, or the decision to submit it.

\section{Description of authors' roles}

Fieldwork was completed by ZC, SD, and MH. The analysis was completed by ZC and SD. The initial draft of the paper was generated by ZC and SD. All authors had full access to all data in the study and contributed to and approved the final report. SB as guarantor had final responsibility for the decision to submit for publication.

\section{Acknowledgments}

We would like to thank the people with dementia and family carers for their time and contribution to this study.

\section{Supplementary material}

To view supplementary material for this article, please visit https://doi.org/10.1017/S1041610218001357. 


\section{References}

Allsop, J. (2013). Researching Health: Qualitative, Quantitative and Mixed Methods. 2nd ed. London: Sage.

Alushi, L., Hammond, J. and Wood, J. (2015). Evaluation of dementia education programs for pre-registration healthcare students - a review of the literature. Nurse Education Today, 35, 992-998. doi: 10.1016/j.nedt.2015.04.006.

Banerjee, S. (2015). Multimorbidity-older adults need health care that can count past one. Lancet, 385, 587-589. doi: 10.1016/S0140-6736(14)61596-8.

Banerjee, S. et al. (2016). How do we enhance undergraduate healthcare education in dementia? A review of the role of innovative approaches and development of the time for dementia programme. International fournal of Geriatric Psychiatry, 32, 68-75. doi: $10.1002 /$ gps.4602.

Black, B., Wechsler, M. and Fogarty, L. (2013). Decision making for participation in dementia research. American Fournal of Geriatric Psychiatry, 21, 355-363. doi: 10.1016/j. jagp.2012.11.009.

Bunn, F. et al. (2014). Comorbidity and dementia: a scoping review of the literature. BMC Medicine, 12, 192. doi: 10 .1186/s12916-014-0192-4.

Bunn, F. and Sworn, K. (2012). Psychosocial factors that shape patient and carer experiences of dementia diagnosis and treatment: a systematic review of qualitative studies. PLOS Medicine, 9, e1001331. doi: 10.1371/journal.pmed.1001331.

Department of Health. (2009). Living Well with Dementia: A National Dementia Strategy. London: HMSO.

Department of Health. (2013). Delivering high quality, effective, compassionate care: Developing the right people with the right skills and the right values: $A$ mandate from the Government to Health Education England: April 2015 to March 2016. UK: HMSO.

Department of Health. (2015). Prime minister's challenge on dementia 2020. UK: Department of Health.

Department of Health. (2016). Making a Difference in Dementia: Nursing Vision and Strategy. UK: HMSO.

Dewing, J. and Dijk, S. (2016). What is the current state of care for older people with dementia in general hospitals? A literature review. Dementia (London), 15, 106-124. doi: $10.1177 / 1471301213520172$.

Douglas-Dunbar, M. and Gardiner, P. (2007). Support for carers of people with dementia during hospital admission. Nursing Older People, 19, 27-30. doi: 10.7748/nop2007.10 .19.8.27.c6269.
Downs, M. and Lord, K. (2017). Person-centered dementia care in the community: a perspective from the United Kingdom. Fournal of Gerontological Nursing, 43, 11-17. doi: 10.3928/00989134-20170515-01.

Folstein, M. F., Folstein, S. E. and McHugh, P. R. (1975). "Mini-mental state". A practical method for grading the cognitive state of patients for the clinician. Fournal of Psychiatric Research, 12, 189-198. doi: 10.1016/0022-3956 (75)90026-6.

Glaser, B. and Strauss, A. (1967). The Discovery of Grounded Theory: Strategies for Qualitative Research. Chicago: Aldine.

Jefferson, A., Cantwell, N., Byerly, L. and Morhardt, D. (2012). Medical student education program in Alzheimer's disease: the PAIRS program. BMC Medical Education, 12, 80. doi: $10.1186 / 1472-6920-12-80$.

Jurgens, J., Clissett, P., Gladman, R. and Harwood, H. (2012). Why are family carers of people with dementia dissatisfied with general hospital care? A qualitative study. BMC Geriatrics, 12, 57. doi: 10.1186/1471-2318-12-57.

Mody, L. et al. (2008). Recruitment and retention of older adults in aging research. Fournal of the American Geriatrics Society, 56, 2340-2348. doi: 10.1111/j.1532-5415.2008 $.02015 . x$.

Morhardt, D. (2006). Educating medical students on Alzheimer's disease and related disorders: an overview of the Northwestern University Buddy program. Dementia, 5, 448-456. doi: 10.1177/147130120600500311.

Morhardt, J. (2014). The effects of an experiential learning and mentorship program pairing medical students and persons with cognitive impairment: a qualitative content analysis. 75, ProQuest Information E Learning, US [Online]. Available at: http://search.ebscohost.com/login.aspx?direct $=$ true $\& \mathrm{db}=$ psyh $\& \mathrm{AN}=2014-99210-024 \&$ site=ehost-live.

QSR International. (2015). NVivo qualitative data analysis software. Version 11.: QSR international Pty Ltd. Available at: http://www.qsrinternational.com/support/faqs/ how-do-i-cite-nvivo-10-nvivo-9-or-nvivo-8-in-my-wo.

Sugarman, J., Cain, C., Wallace, R. and Welsh-Bohmer, A. (2001). How proxies make decisions about research for patients with Alzheimer's disease. Fournal of the American Geriatrics Society, 49, 1110-1119. doi: 10.1046/j.1532-5415 .2001.49218.x.

Watson, L., Ryan, L., Silverberg, N., Cahan, V. and Bernard, A. (2014). Obstacles and opportunities in Alzheimer's clinical trial recruitment. Health Aff (Millwood), 33, 574-579. doi: 10.1377/hlthaff.2013.1314. 